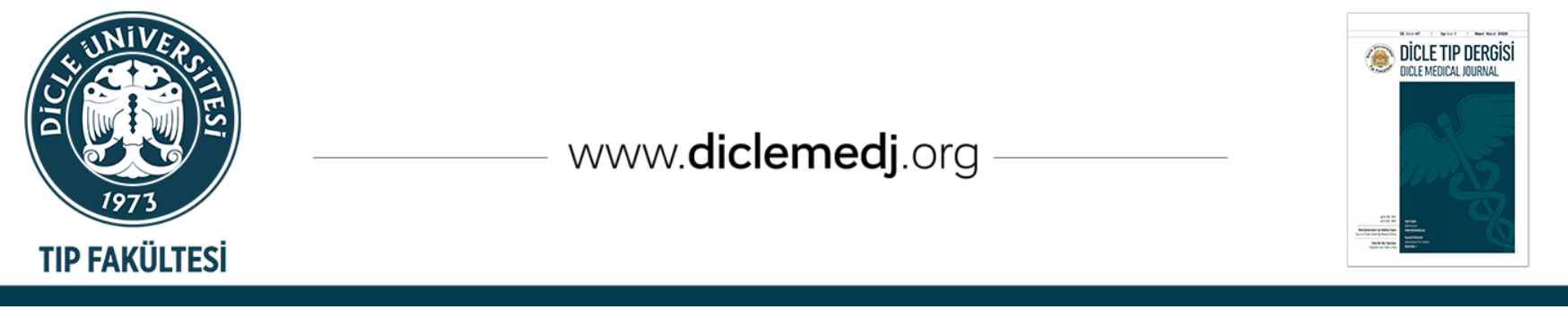

Özgün Araștırma / Original Article

\title{
A Grubu Beta-Hemolitik Streptokok Tanısının Kültür ve Hızlı Antijen Testi ile Değerlendirilmesi
}

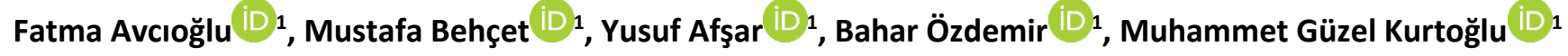 \\ 1 Bolu Abant İzzet Baysal Üniversitesi Tıbbi Mikrobiyoloji Anabilim Dalı Bolu, Türkiye
}

Geliş: 15.01.2020; Revizyon: 13.04.2020; Kabul Tarihi: 04.05.2020

Öz

Amaç: Streptococcus pyogenes olarak da bilinen Grup A streptokok(GAS ), çocuklarda üst solunum yolu (farenjit) enfeksiyonlarının yaygın bir nedenidir. Streptokoksik ve non-streptokoksik farenjit belirtileri ve semptomları birbirlerine çok benzediği için ayırımında laboratuvar testleri büyük önem taşır. GAS tespitinde kültür ve hızlı antijen testleri(HAT) kullanılmaktadır. Ancak kanlı agar besiyerine ekilen bir boğaz sürüntüsünün kültür yapılarak değerlendirilmesinin en önemli dezavantajı, kültür sonucunun elde edilmesindeki süredir (bir gece veya daha uzun). Streptokok hızlı antijen tespit testleri, doğrudan hastanın boğazından alınan sürüntüden direkt yapıldığı için daha avantajlıdır. Bu çalışmada HAT yöntemini farklı şekillerde yaparak etkinliğini kültür testine göre değerlendirmeyi amaçladık.

Yöntemler: 01.03.2019-01.06.2019 tarihleri arasında faranjit ön tanısıyla mikrobiyoloji laboratuvarına gönderilen 368 boğaz sürüntüsü örneği değerlendirmeye alındı. Çalışma iki basamaklı olarak yürütüldü. Birinci aşamada bütün boğaz sürüntü örneklerine hızlı antijen testi (Ecotest ${ }^{\circledR}$ strep A hızlı test / Wellkang, İngiltere) ve kültür ekimi yapıldı. İkinci aşamada kültürde üreme saptanan beta hemolitik kolonilere hem HAT yapıldı hem de kanlı agar besiyerine tekrar pasajlanarak basitrasin ve trimetoprim-sulfometaksazol(SXT) diskleri yerleştirildi.

Bulgular: İşleme alınan 368 boğaz sürüntüsü örneğinin 61'nde(\%17) kültür ile GAS tespit edildi. Birinci aşamada HAT’nin kültüre göre duyarlılığı \%52, özgüllüğü \%100 olarak bulundu. İkinci aşamadaki HAT’nin kültüre göre duyarlıllğı \%92, özgüllüğü \%100 olarak bulundu.

Sonuç: Kültürde üreyen kolonilere HAT yapılmasının GAS tespitini kolaylaştırdığı bu çalışma ile anlaşılmıştır.

Anahtar kelimeler: Streptococcus pyogenes, kültür, hızlı antijen testi

DOI: 10.5798/dicletip.755759

Correspondence / Yazıșma Adresi: Fatma Avcıoğlu, Tıbbi Mikrobiyoloji Anabilim Dalı, Bolu Abant İzzet Baysal Üniversitesi Tıp Fakültesi, Bolu, Türkiye email:fatmaavcioglu@yahoo.com.tr 


\title{
Evaluation of Group A Beta-Hemolytic Streptococcus Diagnosis by Culture and Rapid Antigen Test
}

\begin{abstract}
Objective: Group A streptococci (GAS), also known as Streptococcus pyogenes, is a common cause of upper respiratory tract infections (pharyngitis) in children. Since the symptoms of streptococcal and non-streptococcal pharyngitis are very similar, laboratory tests are very important in differentiating these two infections. Culture and Rapid antigen tests (RAT) are used to detect GAS. However, the most important disadvantage of culturing a throat swab sown on a blood agar medium is the time it takes to obtain the culture result (overnight or longer). Streptococcal rapid antigen detection tests are more advantageous as they are performed directly from the swab taken directly from the patient's throat. In this study, we aimed to evaluate the effectiveness of RAT method in different ways according to culture test.
\end{abstract}

Method: A total of 368 throat swab samples submitted to microbiology laboratory with suspicion of pharyngitis were evaluated between 1 March 2019 and 1 June 2019. The study was conducted in two steps. In the first step, all throat swab samples were analysed with RAT (Ecotest ${ }^{\circledR}$ strep A rapid test kit / Wellkang, UK) and culture. In the second stage, culture- grown beta-haemolytic colonies were analysed by HAT and after subculturing to the blood agar medium, bacitracin and trimethoprim-sulfomethetaxazole (SXT) discs were placed.

Results: GAS was detected in 61 (17\%) of 368 throat swab samples by culture. In the first stage, the sensitivity and specificity of RAT compared to culture were found to be $52 \%$ and $100 \%$, respectively. The sensitivity and specificity of RAT in the second stage were $92 \%$ and $100 \%$, respectively.

Conclusions: It was understood with this study that analaysing HAT to the colonies grown in culture facilitates GAS detection.

Keywords: Streptococcus pyogenes, culture, rapid antigen test

\section{GíRiş}

Streptococcus pyogenes olarak da bilinen Grup A streptokok (GAS ), çocuklarda üst solunum yolu (farenjit) ve cilt (impetigo, pyoderma) enfeksiyonlarının yaygın bir nedenidir. GAS'un tanı ve tedavisinin gecikmesi durumunda romatizmal ateş ve akut glomerülonefrit gibi komplikasyonlara sebep olabilir ${ }^{1}$.

İnsanlar, GAS'ın doğal rezervuarıdır. $\mathrm{Bu}$ bakteriler oldukça bulaşıcıdır ve her yaşta görülebilir. Faringeal enfeksiyonların görülme sıklığı, 5-15 yaş arası çocuklarda, özellikle de genç yaştaki çocuklarda en yüksektir. $\mathrm{Bu}$ enfeksiyonlar, Amerika Birleşik Devletleri'nin kuzey bölgelerinde, özellikle kış ve ilkbaharın ilk aylarında en sık görülür².Türkiye'de de aynı şekilde kış ve ilkbaharın başında bu enfeksiyonlar daha sık görülür.

Akut farenjit ile başvuran bir hastaya tanısal test yapılıp yapılmayacağına karar verirken, klinik ve epidemiyolojik bulgular göz önünde bulundurulmalıdır. Streptokok ve nonstreptokok farenjit belirtileri ve semptomları birbirlerine çok benzediği için ayırımında laboratuvar testleri büyük önem taşır ${ }^{3}$.

Kanlı agar besiyerine ekilen bir boğaz sürüntüsünün kültürü, GAS varlığının gösterilmesi ve akut GAS farenjitinin klinik teşhisinin doğrulanması için yeterlidir. Doğru yapıldığında, tek bir boğaz sürüntüsü farenks içindeki GAS varlığını tespit etmek için \% 90-95 arasında bir duyarlılığa sahiptir. Ancak kanlı agar besiyerine ekilen bir boğaz sürüntüsünün kültür yapılarak değerlendirilmesinin en önemli dezavantajı, kültür sonucunun elde edilmesindeki süredir (bir gece veya daha uzun). Streptokok hızlı antijen tespit testleri (HAT), hastanın boğazından alınan sürüntüden direkt yapıldığı için daha avantajlıdır. Kültür sonucuna göre avantajları, genellikle 10-15 dakikada sonuç vermesidir. GAS tanısının erken konulması, yayılma riskini azaltır, hastanın okula ya da daha erken iş hayatına dönmesine neden olur4-6. 
Çalıșmamızın amacı laboratuvarımıza gönderilen boğaz sürüntüsü örneklerinde GAS tanısı için kültür ve hızlı antijen testinin farklı şekillerde(Kültür öncesi direk hızlı test, kültür sonrası direkt koloniden) kullanımının etkinliğinin ve gerekliliğinin değerlendirilmesidir. Ayrıca bu çalışma ile direkt hastanın boğaz sürüntüsü örneğinden yapılan HAT ile kültürde üreyen şüpheli kolonilere yapılan HAT duyarlılıklarının karşılaştırılması amaçlanmıştır.

\section{YÖNTEMLER}

Bolu Abant İzzet Baysal Üniversitesi tarafından 2019/236 karar numarasıyla etik kurul onayı verilen çalışmamızda 01.03.2019-01.06.2019 tarihleri arasinda faranjit ön tanısıyla mikrobiyoloji laboratuvarına gönderilen 368 boğaz sürüntüsü örneği değerlendirmeye alındı. Boğaz kültürü için sürüntü örnekleri posterior farenks ya da tonsiller bölgeden, dil ya da uvuladan temastan kaçınılarak doktorlar tarafından eküvyon çubuğu (BD BBLTM CultureSwabTM EZ II /Le Pont de Claix, Fransa) ile alınd.

Çalışmamız iki basamaklı olarak yürütüldü. Birinci așamada bütün boğaz sürüntü örneklerine hızlı antijen testi (Ecotest ${ }^{\circledR}$ strep A hızlı test / Wellkang, İngiltere) yapıldı. Daha sonra boğaz sürüntüleri kültür için $\% 5$ koyun kanlı agar ve basitrasinli kanlı agar besiyerine ekildi. Bir gece $35 \pm 2{ }^{\circ} \mathrm{C}^{\prime}$ de etüvde inkübe edildi. Kanlı agar besiyerinde üreyen ama basitrasinli kanlı agarda üremeyen şüpheli beta hemolitik kolonilere; Gram boyama, katalaz testi ve PYR testi yapıldı. İkinci aşamada üreme saptanan bu koloniler kanlı agar besiyerine tekrar pasajlanarak basitrasin ve trimetoprimsulfomtetaksazol(SXT) diskleri yerleştirildi. Aynı zamanda kanlı agar besiyerinde üreyen bu beta hemolitik kolonilere HAT yapıldı. Böylece hem hastadan alınan boğaz sürüntü örneklerine hem de besiyerinde üreyen şüpheli beta hemolitik kolonilere HAT yapıldı. Testlerin sonucunda elde edilen pozitiflik oranları karşılaştırılarak değerlendirildi. Duyarlılık ve özgüllük hesaplamalarında tanı tarama testlerinden yararlanıldı.

\section{BULGULAR}

İșleme alınan 368 boğaz sürüntüsü örneğinin 61'nde (\%17) GAS tespit edildi. Değerlendirmeye alınan örneklerin 298'i (\%81) çocuk polikliniğinden, 41'i (\%11) Kulak Burun Boğaz polikliniğinden, 22'si (\%6) dahiliye polikliniğinden, yedisi (\%2) diğer polikliniklerden gönderilmiştir. Hastadan alınan boğaz sürüntüsü örneklerinden direk olarak yapılan HAT'ne göre yalnızca 32 (\%9) hastada pozitif sonuç bulundu. Birinci aşamada HAT'nin kültüre göre duyarlılığı $\% 52$, özgüllüğü \%100 olarak bulundu. İkinci aşamada aynı örneklerden yapılan kültür ekimi sonrasında 74 örnekte şüpheli beta hemolitik koloniler tespit edildi. GAS açısından şüphelenilen bu 74 örnek ikinci kez kanlı agar besiyerine pasajlandığında 61 izolat basitrasine duyarlı SXT'ye dirençli olarak saptandı (Şekil 1). Kültürden yapılan HAT'ne göre 56 örnekte pozitif sonuç tespit edildi. İkinci aşamadaki HAT’nin kültüre göre duyarlılığı $\% 92$, özgüllüğü $\% 100$ olarak bulundu. Kültür ve HAT’nin birinci ve ikinci basamaktaki karşılaştırmalı sonuçları Tablo I ve Tablo II'de gösterildi.

Tablo I: Kültür ve Hizlı Antijen Test(Hastadan)Sonuçlarının Karşılaştırılması

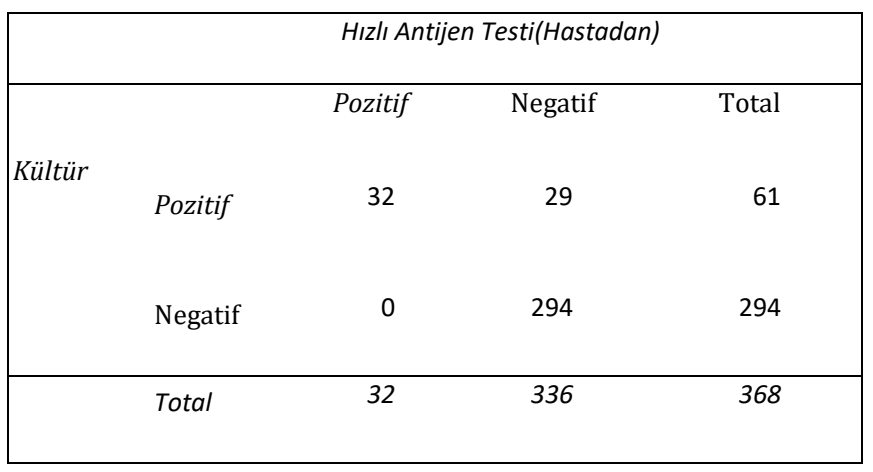


Tablo II: Kültür ve Hızlı Antijen Test(Kültürden) Sonuçlarının Karşılaştırılması

\begin{tabular}{|c|c|c|c|c|}
\hline & \multicolumn{4}{|c|}{ Hızlı Antijen Testi(Kültürden) } \\
\hline \multirow{5}{*}{ Kültür } & & Pozitif & Negatif & Total \\
\hline & Pozitif & 56 & 5 & 61 \\
\hline & Negatif & 0 & 13 & 13 \\
\hline & & & & 74 \\
\hline & Total & 56 & 18 & \\
\hline
\end{tabular}

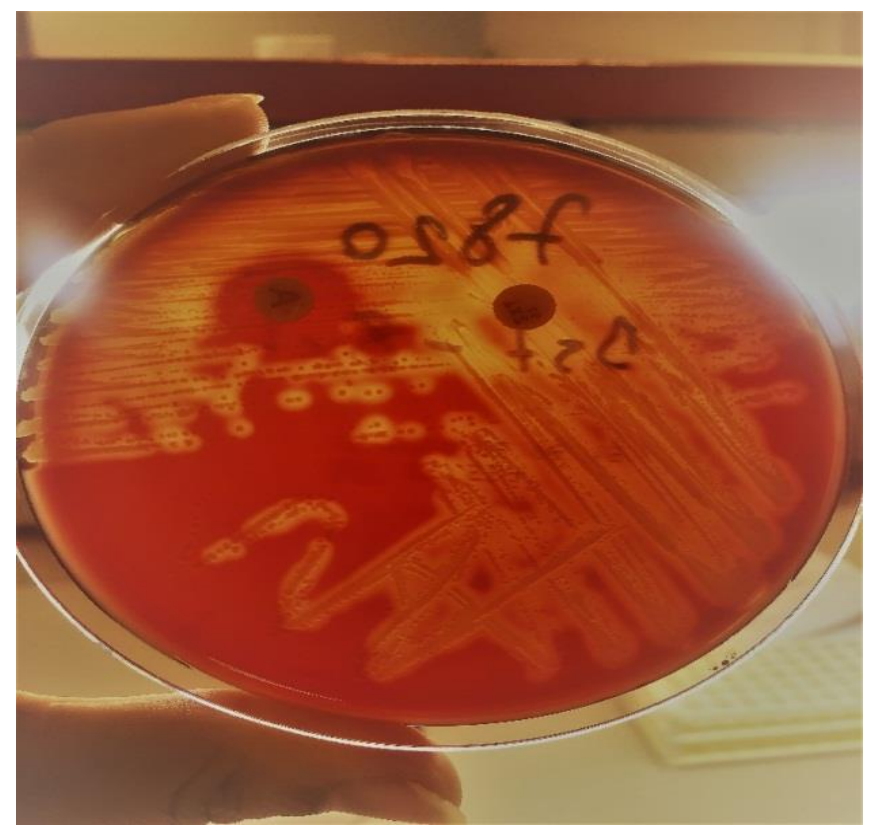

Şekil 1. Basitrasine(A) duyarl, trimetoprimsulfomtetaksazole(SXT) dirençli GAS'ın Kanlı agardaki görüntüsü

\section{TARTIŞMA}

GAS'ın erken tanısı bazı durumlar açısından önemlidir. Bunlardan birincisi tanı ve tedavinin gecikmesi halinde romatizmal ateş ve akut glomerülonefrit gibi komplikasyonların oluşabilmesidir. İkincisi gereksiz antibiyotik kullanımı ve yanlış tedavi maliyetlerinin engellenmesidir ${ }^{7}$. Üçüncüsü ise damlacık yolu ile kolaylıkla bulaşabilen bu enfeksiyonun doğru ve erken tedavisi ile yayılımının önlenmesidir8 ${ }^{8}$ GAS tanısında her zaman kültür altın standart bir yöntem olmuştur. HAT'leri ise sonuç verme süresindeki çabukluğu nedeniyle klinisyenler tarafından çok tercih edilen bir yöntemdir ${ }^{9}$. Dünyada ve ülkemizde pek çok farklı araştırmacı tarafından HAT'lerinin duyarlılığı ve etkinliği ile ilgili çalışmalar yapılmıştır. Dünyada yapılan çalışmalara göre hızlı antijen testlerinin duyarlılığı \%65,6-96,4, özgüllüğü \%68,7-99,3, pozitif ve negatif prediktif değerleri sirasıyla \%87,8-98 ve \%59,4-97,4 aralığında belirlenmiştir ${ }^{10}$. Ülkemizde ise farklı test kitleri ve örneklem guruplarının değişkenliği göz önünde bulundurularak yapilan çalışmalarda duyarlıklık \%59,5-100, özgüllük \%92,2-100 aralığında tespit edilmiştir ${ }^{7,9-13}$. Bu çalışmada ise elde ettiğimiz duyarlılık birinci-ikinci basmaklarda sırasıyla \%52 ve \%92, özgüllük ise \%100 olarak bulunmuş olup ikinci basamakta kültürden yapılan HAT'lerinin duyarlılığının daha yüksek olduğu kanaaatine varılmıştır.

GAS’a bağlı akut tonsillofaranjit insidansı \%2840 arasında değişmektedir. Görülme sıklığı bölgelerin sosyoekonomik yapısına, mevsimsel özelliklere vb. bir çok nedene bağlı olarak değişmektedir ${ }^{14}$. Arslan ve ark. ${ }^{15}$ yaptıkları çalışmada ÜSYE tanısı alan hastalarda GAS varlığını \%42 oranında bulmuşlardır. Furuncuoğlu ve ark. ${ }^{16} \% 10,8$ oranında GAS tespit etmişlerdir. Bölgemizde Yılmaz ve ark. ${ }^{14}$ 2008 yılında yaptıkları çalışmada boğaz kültüründe $\quad \% \quad 11,3 \quad$ oranında GAS saptamışlardır. Bu çalışmada GAS varlığını \%17 olarak tespit ettik. 2008 yllında hastanemizde yapılan çalışmaya göre GAS varlığının görülmesinde artış olduğu gözlenmiştir.

$\mathrm{Bu}$ çalışmanın yapılan bir çok değişik HAT’ne göre en büyük farkı HAT'nin ilk aşamada direk hasta örneğinden, daha sonra kültürde üreme tespit edilen kolonilerden yapılmasıdır. Ülkemizde daha önce bu yöntemle yapılan benzer bir çalışma yoktur. Çalışmamızın bu bakımından ilk olması önem arz etmektedir. Kültürden yapılan HAT özgüllügü direk 
hastadan yapılan HAT'ne göre daha yüksek oranda bulunmuştur. Yalancı negatif bulunan örnek sayısı ilk yapılan HAT'de 29 iken ikinci yapılan HAT'de 5 olarak bulunmuştur. Bu da kültürden yapılan HAT'nin GAS'u kaçırma ihtimalinin daha düşük olduğunu göstermiştir. HAT yapılışının farklı metotlarla yapıldığı ve buna göre önerilerin bulunduğu pek çok çalışma vardır. Kurtz ve ark. ${ }^{17}$ ile Bulut ve ark. ${ }^{7}$ ikili sürüntü çubuğu kullanımının antijen testinin performansını yükselttiğini göstermişlerdir. $\mathrm{Bu}$ çalışma tek boğaz sürüntüsü örneği kullanılarak yapılmış olmasına rağmen kültürde üreyen kolonilere HAT yapılmasının GAS tespitini kolaylaştırdığını göstermiştir. Böylelikle normal bir boğaz kültürü için yapılması gereken işlemlerin neticesi 48 saat gibi bir sürede sonuçlanırken bu çalışmada yapılan yöntem ile 24 saatte sonuç verilebileceği gösterilmiștir.

Çalışmamızın sınırlılığı birinci aşamada yapılan kültür testinde üreme açısından şüpheli koloni sayısının beklenenden düşük olmasıdır. Ayrıca tek çeşit HAT kiti kullanılması da diğer bir sinirlliktır.

\section{SONUÇ}

Kültürde şüpheli bulunan GAS kolonilerine HAT’nin yapılması kültürün sonuçlanma süresinin kısalmasına katkı sağladığı bu çalışma ile gösterildi.

Etik Kurul Kararı: Bolu Abant İzzet Baysal Üniversitesi tarafindan 2019/236 karar numarasıyla etik kurul onayı verilen çalışmamızda 01.03.2019-01.06.2019 tarihleri arasında faranjit ön tanısıyla mikrobiyoloji laboratuvarına gönderilen 368 boğaz sürüntüsü örneği değerlendirmeye alındı.

Çıkar Çatışması Beyanı: Yazarlar çıkar çatışması olmadığını bildirmişlerdir.

Finansal Destek: Bu çalışma her hangi bir fon tarafından desteklenmemiştir.
Declaration of Conflicting Interests: The authors declare that they have no conflict of interest.

Financial Disclosure: No financial support was received.

\section{KAYNAKLAR}

1. Ji MJ, Noh JS, Cho BK, et al. Evaluation of SD BIOLINE Chagas Ab rapid kit. Korean J Lab Med 2009; 29: 48-52.

2. Kliegman R, Behrman R, Jenson H, Stanton B. Nelson textbook of pediatrics e-book. Elsevier Health Sciences 2007 Aug 15.

3. Bisno Al, Stevens DL. Streptococcus pyogenes. In: Mandell GL (eds). Mandell, Douglas and Bennett's Principles and Practice of Infectious Diseases, 7th ed.Philadelphia:Churchill Livingston, 2010: 2593-610.

4. Cohen JF, Cohen R, Levy C, et al. Selective testing strategies for diagnosing group $\mathrm{A}$ streptococcal infection in children with pharyngitis: a systematic review and prospective multicentre external validation study. CMAJ 2015; 187: 23-32.

5. Gieseker KE, Roe MH, MacKenzie T, Todd JK. Evaluating the American Academy of Pediatrics diagnostic standard for Streptococcus pyogenes pharyngitis: backup culture versus repeat rapid antigen testing. Pediatrics 2003; 111: 666-70.

6. Gazzano V, Berger A, Benito $Y$, et al. Reassessment of the role of rapid antigen detection tests in diagnosis of invasive group a streptococcal infections. J Clin Microbiol 2016; 54: 994-9.

7. Bulut ME, Aktaş E, Malkoçoğlu G, et al. Is It a Necessity to Use Double Swab in the Detection of Group A Streptococci by the Strep A Rapid Antigen Test? Türk Mikrobiyoloji Cemiy Derg 2019; 49: 30-4.

8. Çoban B, Kaplan H, Topal B, Ülkü N. Grup A Streptokok Tonsillofarenjitinde Hızlı Antijen Testinin Duyarlılığı ve Özgüllüğü 
Tonsillofarenjitte Hızlı Antijen Testi. Cocuk Enfeksiyon Derg 2013; 7: 143-6.

9. Milletli-Sezgin F, Ünlü E. Evaluation of rapid antigen test in child patients with group A streptococcal tonsillopharyngitis. Turk Hij Den Biyol Derg 2019; 76: 329-34.

10. Ruiz-Aragón J, López RR, Linde JMM. Evaluation of rapid methods for detecting Streptococcus pyogenes. systematic review and meta-analysis. Anales de Pediatría 2010; 72: 391-402.

11. Saygılı N, Bulut E, Deniz R, Dalgıç N, Aktaş E. Use of Bionexia Strep A Plus Rapid Antigen Test in the Identification of Group A Beta-Hemolytic Streptococci in Throat Swab Samples. Türk Mikrobiyoloji Cemiy Derg 2017; 47: 138-45.

12. Bulut Me, Yücel E, Deniz R, Bariş A, Anliaçik N, Aktaş E. Evaluation of Mascia Brunelli Rapid Antigen Test in the Diagnosis of Group A Streptococcal Pharyngitis. Mikrobiyol Bul 2017; 51: 73-8.

13. Yücel S. A Grubu Beta Hemolitik Streptokokların 1. Basamak Sağlık Kuruluşlarında Tanısı ve Gereksiz Antibiyotik Kullanımı. STED / Sürekli Tıp Eğitimi Derg 2018; 27: 205-8.
14. St Sauver JL, Weaver AL, Orvidas LJ, Jacobson RM, Jacobsen SJ. Population-based prevalence of repeated group A beta-hemolytic streptococcal pharyngitis episodes. Mayo Clin Proc 2006; 81: 1172- 6.

15. Arslan M, Elbir Şahin A, Gülsever O, et al. Clinical scoring for distinction of bacterial and viral upper respiratory tract infections of children. Aile Hekim ve Palyatif Bakım 2017; 2: 6-11.

16. Furuncuoğlu Y, Başar M, Alıcı Ö, Bayiz Ü. The incidence of group a beta hemolytic streptococci in patients with acute exudative tonsilitis in İstanbul, a 14-year period. İstanbul Tıp Fakültesi Derg 2016; 79: 16-8.

17. Kurtz B, Kurtz M, Roe M, Todd J. Importance of inoculum size and sampling effect in rapid antigen detection for diagnosis of Streptococcus pyogenes pharyngitis. J Clin Microbiol 2000; 38: 279-81. 